\title{
EHMTI-0055. Abnormal thalamic function in patients with vestibular migraine
}

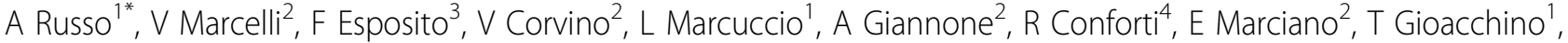 \\ A Tessitore
}

From 4th European Headache and Migraine Trust International Congress: EHMTIC 2014

Copenhagen, Denmark. 18-21 September 2014

\section{Introduction}

Vestibular migraine (VM) has been increasingly recognized as a possible cause of episodic vertigo, but its pathophysiology is still unclear.

\section{Aims}

We used advanced non-invasive neuroimaging to examine the functional response of neural pathways associated with vestibular stimulation in patients with VM.

\section{Methods}

Twelve patients with VM underwent whole-brain blood oxygen level-dependent (BOLD) fMRI during ear irrigation with cold water. The functional response of neural pathways to this stimulation in patients with VM was compared to age- and gender-matched patients with migraine without aura (MwoA) and healthy controls (HC). Secondary analyses explored associations between BOLD signal change and clinical features of migraine in patients.

\section{Results}

We observed a robust cortical and subcortical pattern of BOLD signal change in response to ear irrigation across all participants. Patients with VM showed significantly increased thalamic activation in comparison with both patients with MwoA and HC. The magnitude of thalamic activation was positively correlated with the frequency of migraine attacks in patients with VM.

\section{Conclusions}

We provide novel evidence for abnormal thalamic functional response to vestibular stimulation in patients with

${ }^{1}$ Department of Medical Surgical Neurological Metabolic and Aging Sciences, Second University of Naples, Naples, Italy

Full list of author information is available at the end of the article
VM. These functional abnormalities in central vestibular processing may contribute to VM pathophysiology.

No conflict of interest.

\section{Authors' details}

'Department of Medical Surgical Neurological Metabolic and Aging Sciences, Second University of Naples, Naples, Italy. ${ }^{2}$ Department of Neuroscience, University of Naples "Federico II", Naples, Italy. ${ }^{3}$ Department of Medicine and Surgery, University of Salerno, Baronissi (Salerno), Italy. ${ }^{4}$ Department of Clinical and Experimental Medicine and Surgery "F. Magrassi-A. Lanzara", Second University of Naples, Naples, Italy.

Published: 18 September 2014

doi:10.1186/1129-2377-15-S1-E32

Cite this article as: Russo et al:: EHMTI-0055. Abnormal thalamic

function in patients with vestibular migraine. The Journal of Headache and Pain 2014 15(Suppl 1):E32.

\section{SpringerOpen ${ }^{\circ}$}

(c) 2014 Russo et al; licensee Springer. This is an Open Access article distributed under the terms of the Creative Commons Attribution License (http://creativecommons.org/licenses/by/2.0), which permits unrestricted use, distribution, and reproduction in any medium, provided the original work is properly cited.
Submit your manuscript to a SpringerOpen ${ }^{\circ}$ journal and benefit from:

- Convenient online submission

- Rigorous peer review

- Immediate publication on acceptance

- Open access: articles freely available online

- High visibility within the field

- Retaining the copyright to your article

Submit your next manuscript at $>$ springeropen.com 